\title{
BMP-4 induces a Smad-dependent apoptotic cell death of mouse embryonic stem cell-derived neural precursors
}

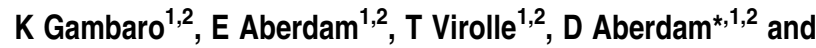 \\ M Rouleau*,1,2 \\ 1 INSERM, U634, Nice F-06107, France \\ 2 Université de Nice-Sophia Antipolis, Nice F-06107, France \\ * Corresponding authors: D Aberdam, INSERM U634, Faculté de Médecine \\ Nice Sophia Antipolis, Av de Valombrose, 06107 Nice Cedex 2, France. \\ Tel: + 33-4-93-37-77-18; Fax: + 33-4-93-81-14-04; \\ E-mail: aberdam@unice.fr \\ or M Rouleau, Tel: + 33-4-93-37-77-47; Fax: + 33-4-93-81-14-04; \\ E-mail: rouleau@unice.fr
}

Received 21.3.05; revised 01.9.05; accepted 23.9.05; published onilne 25.11.05 Edited by $\mathrm{G}$ Cossu

\begin{abstract}
Embryonic ectoderm is fated to become either neural or epidermal, depending on patterning processes that occur before and during gastrulation. It has been stated that epidermal commitment proceeds from a bone morphogenetic protein-4 (BMP-4)-dependent inhibition of dorsal ectoderm neuralization. We recently demonstrated that murine embryonic stem (ES) cells treated with BMP-4 undergo effective keratinocyte commitment and epidermogenesis. Focusing on the precise role of BMP-4 in the early choice between neural and epidermal commitment, we show here that BMP-4 treatment of ES cells leads to a dramatic apoptotic death of Sox-1 ${ }^{+}$neural precursors with concomitant epidermal engagement. In addition, neutralization of the Smad pathway prevents both the BMP-4 apoptotic process and the inhibition of neural differentiation. Our results suggest that, in mammals, BMP-4, as an active inducer of epidermal commitment, interferes with the survival of neural precursors through induction of their apoptotic cell death.

Cell Death and Differentiation(2006) 13, 1075-1087.

doi:10.1038/sj.cdd.4401799; published online 25 November 2005
\end{abstract}

Keywords: BMP-4; mouse ES cells; apoptosis; neural precursors; Sox-1

Abbreviations: AdV, adenovirus; BMP, bone morphogenetic protein; CHX, cycloheximide; DiOC6(3), 3,3' dihexyloxacarbocyanine iodide; ES, embryonic stem; FSC, forward scatter; MOI, multiplicity of infection; PI, propidium iodide; SSC, side scatter; $\Delta \Psi \mathrm{m}$, transmembrane mitochondrial potential

\section{Introduction}

During vertebrate gastrulation, cells derived from the ectoderm are segregated into neural or epidermal primordia depending on signals delivered from the organizer tissue. Both ectoderm and mesoderm are patterned along the dorsoventral (DV) axis, governed by the morphogenetic and instructive effect of bone morphogenetic proteins (BMPs) (for a review, see Hogan. ${ }^{1}$ ) BMP-4, a member of the transforming growth factor-beta (TGF- $\beta$ ) superfamily, is a morphogen that is secreted early during the late blastula stage by the ventral embryonic region. It promotes the specification of ventral cell fates, and its action is counterbalanced by the secretion of dorsal antagonists (Noggin, Chordin, Follistatin), leading to a DV axis gradient of functional BMP-4 (for a review, see Hogan ${ }^{1}$ ). At the ectodermal level, BMP-4 behaves like a strong epidermal inducer in regions with low antagonist concentrations (ventral region of the ectoderm), while high levels of BMP-4 antagonists in the dorsal region induce the formation of the neuroectoderm during Xenopus development and probably more generally in vertebrate development. ${ }^{2,3}$

For the ectoderm, this indirect and inhibitory mode of the dorsal organizer action is described in the 'neural default' model, according to which ectodermal cells will undergo neural differentiation unless instructed by BMPs not to do so, and to become epidermal. ${ }^{2}$ Numerous studies in Xenopus laevis support this 'default' model to explain the neural cell fate determination. In mammals, little experimental data are available regarding the mechanisms underlying early neural and ectodermal differentiation. ${ }^{4}$ Gene deletion experiments in mouse embryos have not been conclusive regarding the role of BMP and its antagonists in such a commitment. However, differentiation of mouse embryonic stem (ES) cells appears to be a potent in vitro model to study embryonic neural induction in mammals. A high level of neural differentiation has been obtained through aggregation of ES cells with retinoic acid treatment in the presence of serum, ${ }^{5}$ or by the coculture of ES cells with the PA6 stromal cell line in the absence of serum. ${ }^{6}$ In both cases, the addition of BMP-4 suppressed neural differentiation in a time-dependent manner, while it promoted mesodermal ${ }^{5}$ or ectodermal engagement. ${ }^{6}$ The attenuation of BMP signaling in ES cells appears to be essential but not sufficient for neural induction, since its specific blockade does not significantly promote neural differentiation, suggesting that some additional signals are required for mammalian neural induction. Recent data have shown that, in the absence of feeder-derived or serum-derived factors and at low cell densities, ES cells undergo a direct phenotypic change towards the neural fate, ${ }^{7}$ a process that requires autocrine fibroblast growth factor (FGF). ${ }^{8}$ Nevertheless, BMP-4 appears to be the central mediator in the switch from neuronal to epidermal commitment. The target genes regulated by the BMP signaling pathway and their roles during the specification of ventral cell types are poorly understood. The homeobox Msx gene family is known to be activated by BMP signals during morphogenesis and cell differentiation. Among them, the Msx-1 transcription factor has been shown to mediate the 
BMP signaling in epidermal induction and inhibition of neural differentiation in Xenopus development. ${ }^{9}$ However, the mechanism leading to inhibition of early neural cell fate determination through the interaction of BMP-4 with the neuroectoderm is not known.

Several lines of evidence suggest that the activity of BMPs is associated with developmentally regulated apoptosis. ${ }^{10,11}$ In particular, BMP-4 triggers apoptosis in prospective neural crest cells, ${ }^{12}$ in the dorsal portion of the chick optic cup during morphogenesis of the eye ${ }^{13}$ and in the interdigital space of the developing limbs in birds. ${ }^{14}$ Similarly, BMP responses lead to apoptosis of committed populations of neural stem cells isolated from progressively older fetuses, and then to neuronal and finally glial differentiation. ${ }^{15,16}$ We recently reported the ability of BMP-4 to efficiently promote murine ES cell differentiation towards epidermal fate and skin organogenesis in vitro. ${ }^{17}$ In the present study, we show that a high proportion of ES cells, engaged in differentiation towards neural cell types, undergo a dose- and timedependent apoptotic cell death when treated early with BMP-4. This apoptotic cell death involves the characteristic mitochondrial damages leading to the cleavage of caspase-3 and targets early neural Sox-1 positive precursor cells. We further demonstrate that this mechanism does not involve the p38 MAP kinase pathway usually associated with BMP proapoptotic effects, ${ }^{18}$ but proceeds rather through the activation of both the Smad pathway and Msx1/2 gene expression. Altogether, our results indicate that part of the inhibition of neuralization by BMP-4, in mammals, involves the apoptotic cell death of neural precursor cells, resulting in enrichment of epithelial/epidermal lineages.

\section{Results}

\section{BMP-4 inhibits the differentiation of mouse ES cells into neural precursors and promotes epidermal commitment}

Neuronal differentiation of ES cells was induced using a protocol described elsewhere. ${ }^{6}$ Seeded on fixed fibroblastic feeder cells in the absence of serum, mouse ES cells differentiated efficiently within 7 days into neural precursors,
A

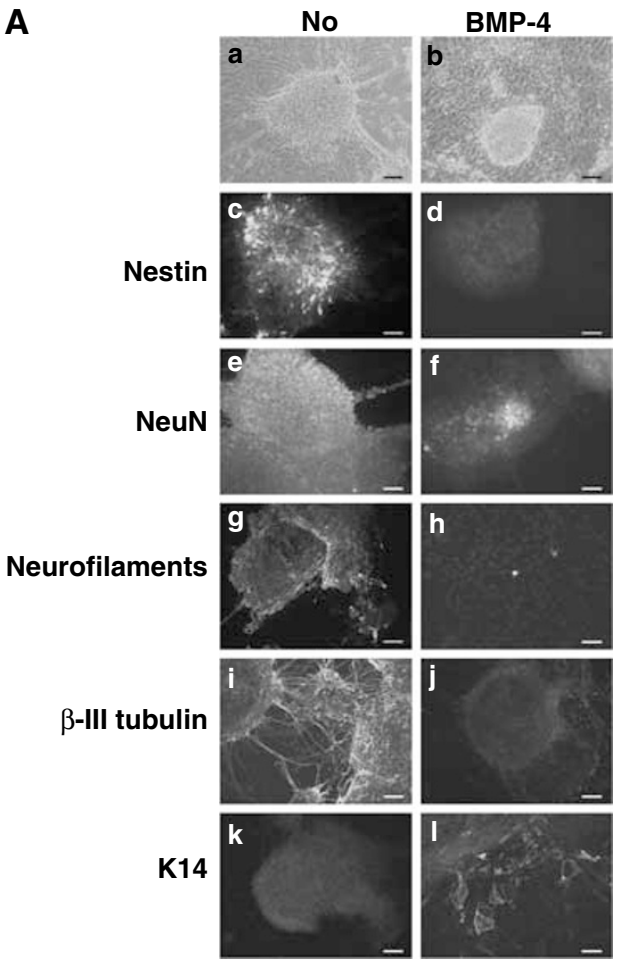

B
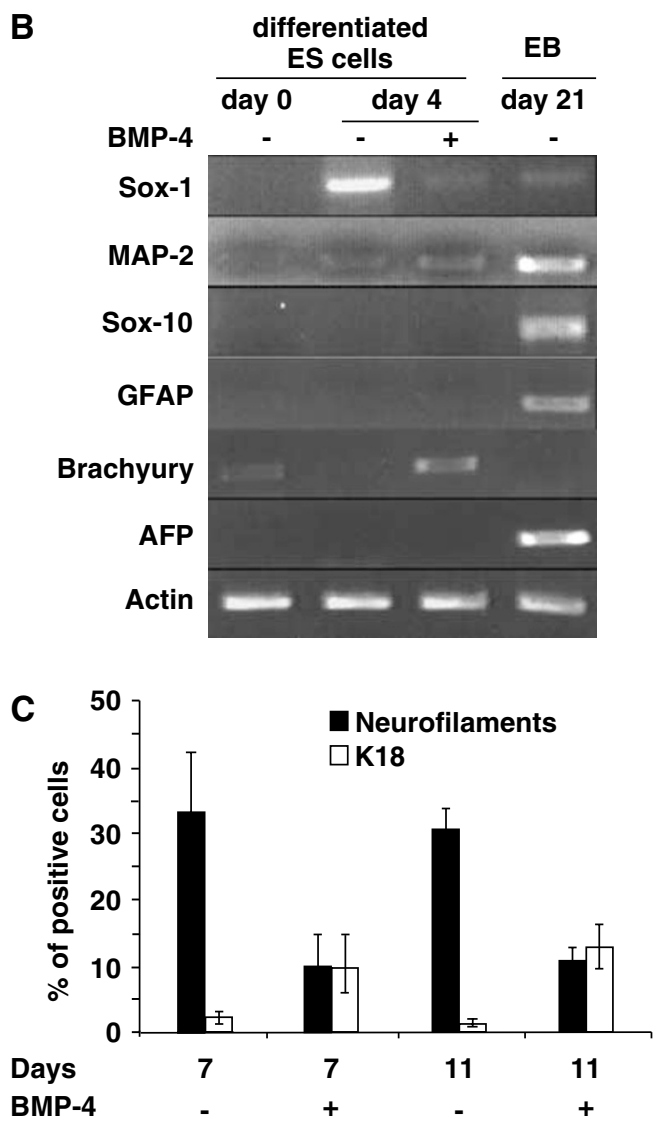

Figure 1 BMP-4 suppresses neural differentiation of ES cells and promotes epidermal commitment. (A) Phase contrast (a, b) and immunofluorescent staining (c-l) of ES cells cultured on fixed NIH-3T3 cells for 7 ( $c-j)$ to 11 days $(a, b, k$ and I) under serum-free conditions. BMP-4 treatment applies from day 3 to day 6 . In (k) and (l), serum was added during the last 2 days of the 11 day induction before cells were stained with cytokeratin 14 antibodies. Scale bars represent $100 \mu \mathrm{m}$ in $(\mathrm{g}-\mathrm{j})$ and $50 \mu \mathrm{m}$ in $(\mathrm{a}-\mathrm{f}$, $\mathrm{k}$ and I). (B) RT-PCR analysis were performed on total RNA from undifferentiated ES cell (day 0), ES cell at day 4 of differentiation (day 4) untreated or stimulated with BMP-4 for $24 \mathrm{~h}$, and from embryoid bodies (EB) at 21 day of differentiation. AFP (endoderm), Brachyury (mesoderm) and neural subtype markers GFAP (astrocytes), MAP-2 (neurons), Sox-10 (oligodendrocyte precursors) and Sox-1 (neural precursors) were tested. (C) Flow cytometry profiles of neuronal and epithelial commitments of differentiated ES cells. Neurofilament and cytokeratin 18 positive cells were quantified at days 7 and 11 of differentiation with and without BMP-4 treatment (from day 3 to day 6). Data are represented as mean \pm S.D. of three independent experiments performed in triplicate 
Table 1 Percentages of ES-derived colonies positive for neural and neuronal markers at day 4 (D4) and day 6 (D6) of differentiation

\begin{tabular}{lccc}
\hline & \multicolumn{3}{c}{ Percentage of positive colonies } \\
\cline { 2 - 4 } Sox-1 (D4) $^{\mathbf{a}}$ & NeuN (D6) $^{\mathbf{a}}$ & Nestin (D6) $^{\mathbf{a}}$ & Neurofilament (D6) \\
\hline $80.1 \pm 9.7$ & $98.5 \pm 3.4$ & $97.5 \pm 5.6$ & $98.2 \pm 4.5$ \\
\hline
\end{tabular}

${ }^{\mathrm{a}}$ Mean \pm S.D., $n=5$.

Table 2 mRNA levels of Msx-1, -2 and Id-3 gene expression after BMP-4 treatment at day 4 of ES cell differentiation

\begin{tabular}{lccr}
\hline & \multicolumn{3}{c}{ Q-PCR analysis $^{\mathbf{a}}$} \\
\cline { 2 - 4 } BMP-4 treatment (h) & Msx-1 $^{\mathbf{b}}$ & Msx-2 $^{\mathbf{b}}$ & Id-3 $^{\mathbf{b}}$ \\
\hline 2 & $23.8 \pm 0.7$ & $60.8 \pm 0.8$ & $17.3 \pm 0.5$ \\
24 & $36.5 \pm 1.5$ & $111.9 \pm 4.7$ & $5.5 \pm 0.5$
\end{tabular}

a Value expressed as fold induction compared to not treated cells. ${ }^{b}$ Mean \pm S.D., $n=3$.

within large colonies (Figure 1A (a)) positive for four neural progenitor markers: Nestin (Figure 1A (c)), NeuN (Figure 1A (e)), Neurofilaments (Figure $1 \mathrm{~A}(\mathrm{~g})$ ) and $\beta$-III-tubulin (Figure $1 \mathrm{~A}(\mathrm{i}))$. As expected, virtually all colonies were immunoreactive to neural markers at day 6 (Table 1 and Figure S1), and at day 4 of differentiation, $80 \%$ of the colonies were already positive for the neural precursor marker Sox-1 (Table 1 and Figure S1).

Neuronal commitment of ES cells was confirmed at the level of gene expression with the detection of Sox-1 and MAP-2 transcripts at day 4 (Figure 1B). The absence of glial (Sox10, GFAP) markers confirmed the requirement of appropriate culture conditions to induce astrocytic (GFAP) and oligodendrocytic (Sox10) differentiation within this in vitro culture model. ${ }^{6,19}$ Furthermore, no differentiation toward endodermal (AFP) and mesodermal (brachyury) lineages was observed (Figure 1B).

A drastic morphological change in the cell culture was observed when the differentiated ES cells were treated from day 3 to day 6 with BMP $-4(0.5 \mathrm{nM})$. Typically, the large colonies of cells acquired an epithelial phenotype instead of the axonal morphology observed in the absence of BMP-4 treatment. This modification was already evident at day 7 (not shown), and it was completed by day 11 (Figure 1A (b)). Accordingly, rare NeuN, Neurofilament and $\beta$-III-tubulin-positive cells were detected, by immunofluorescence, following BMP-4 treatment (Figure $1 \mathrm{~A}(\mathrm{f}, \mathrm{h}, \mathrm{j})$ ). On the other hand, when the cell cultures were further extended for two additional days in the presence of $10 \%$ bovine serum, large patches of cytokeratin K14-positive cells became apparent (Figure 1A (I)).

A quantitative illustration of this effect could be reported by intra-cellular staining and flow cytometric analysis. The proportion of Neurofilament-positive cells measured at day 7 and 11 of differentiation was largely decreased upon BMP-4 treatment from day 3 to day 6 , while the proportion of cytokeratin K18-positive epithelial cells was enhanced (Figure 1C).
This culture model confirms the dual role of BMP-4 in the differentiation process of mouse ES cells: it can induce a sharp inhibition of the neural engagement while promoting the epidermal commitment.

Msx-1, -2 and Id-3 are early transcription factors known to be induced in response to BMP-4 the course of ES cell differentiation. Total RNAs were extracted 0, 2 and $24 \mathrm{~h}$ after BMP-4 treatment and were tested for Msx-1, Msx-2 and Id3 expression by real-time PCR (Table 2). The results showed that their expression is rapidly activated upon BMP-4 treatment. At $24 \mathrm{~h}$ post-treatment, the transcriptional enhancement was drastic for Msx-1 and Msx-2 genes, but was declining for Id-3.

These results are consistent with the role of BMP-4 and Msx expression in epidermal induction and inhibition of neural differentiation, at least as demonstrated in Xenopus. ${ }^{9}$

\section{BMP-4 induces the apoptotic death of ES cells during the neural differentiation process}

Cell death was reproducibly observed in many ES cell-derived colonies exposed to BMP-4 treatment for $16 \mathrm{~h}$ as compared to control conditions (Figure 2a). Cell death was therefore quantified by flow cytometric analysis using the fluorescent probe DiOC6(3) (3,3' dihexyloxacarbocyanine iodide), monitoring the appearance of apoptotic cells, and propidium iodide (PI) to detect dead cells. At $16 \mathrm{~h}$ after BMP-4 treatment of ES cells induced to differentiate, the percentage of live DiOC6(3) ${ }^{\text {high }} / \mathrm{PI}^{-}$cells was markedly reduced from 65 to $28 \%$. The percentage of $\mathrm{PI}$ positive dead cells and the percentage of apoptotic DiOC6(3) ${ }^{\text {low }} / \mathrm{PI}^{-}$cells were both largely increased (from 6 to $16 \%$, and from 20 to $48 \%$ respectively) (Figure $2 b$ ). The induction of cell death was dose-dependent, with a maximal effect at known physiologic doses of BMP-4 (0.5 nM) (Figure 2c). It also required de novo protein synthesis, since the mitochondrial damage induced by BMP-4 on differentiated ES cells was completely blocked by the use of $10 \mu \mathrm{M}$ cycloheximide (Figure S2).

The specific proteolytic activation of caspases, from the zymogen proform to the active cleaved enzyme, is one of the hallmarks of apoptosis. As mitochondrial damage leads to caspase activation, we tested the effect of caspase inhibition on BMP-4 induced cell death. When cells were preincubated for $4 \mathrm{~h}$ with z-VAD-fmk, a broad specific inhibitor of caspases, the resulting loss of live cells induced by overnight treatment with BMP-4 remained unchanged $(28.0 \%$ with $z-V A D-f m k$ pretreatment versus $31.3 \%$ in the control) (Table 3). On the contrary, the increase in $\mathrm{PI}^{+}$dead cells resulting from BMP-4 treatment was significantly reduced when a caspase inhibitor was used $(4.3 \%$ with z-VAD-fmk pretreatment versus $23.2 \%$ in the control). Alternatively, the increase in cells with reduced $\Delta \Psi \mathrm{m}$ yet not undergoing degradation of their plasma membrane (cells undergoing apoptosis and not dead cells) was increased $(32.8 \%$ with z-VAD-fmk pretreatment versus $12.9 \%$ in the control). These results showed that, in our experimental conditions, BMP-4 treatment induced the activation of caspases, a mechanism that was required for entire cell death process. Futhermore, it emphasizes that the 
a

No
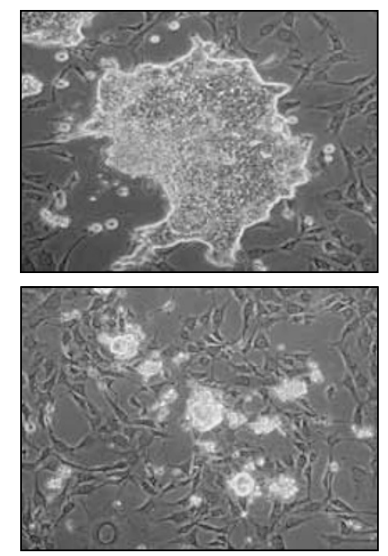

b
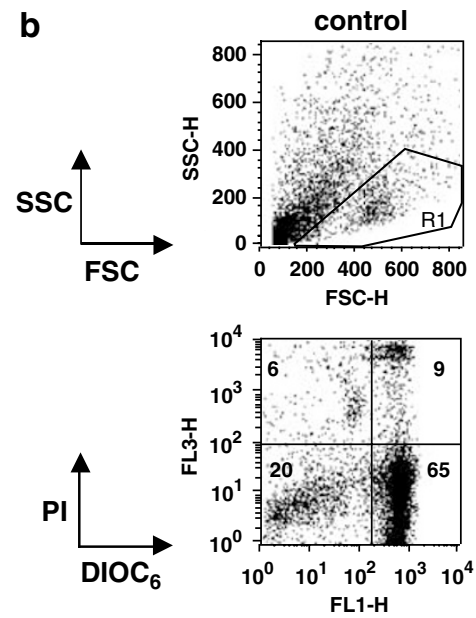

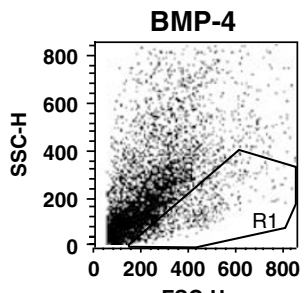

FSC-H

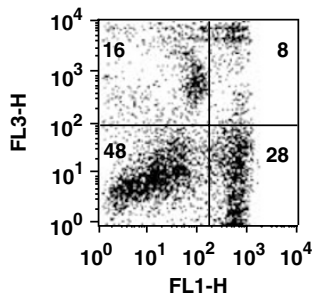

C

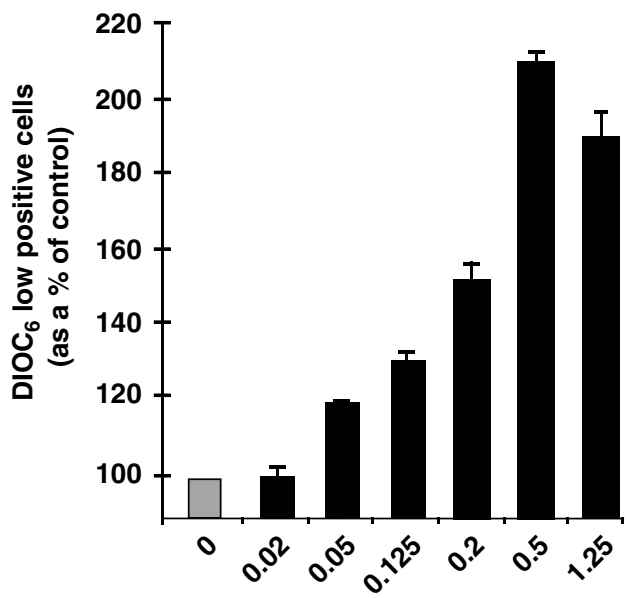

BMP-4 concentration (nM)

d

BMP-4 treatment (time course)

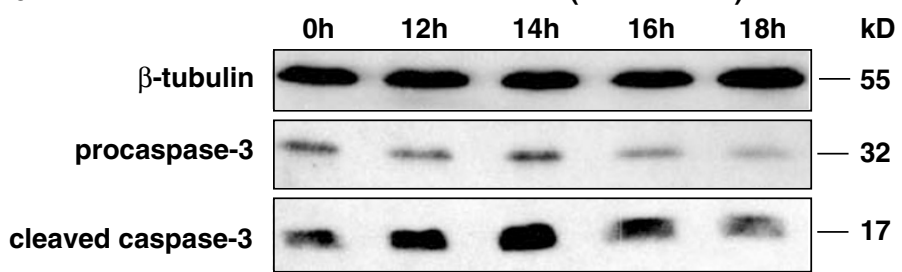

Figure 2 BMP-4 induces a dose-dependent apoptosis of differentiating ES cells. (a) Phase contrast of ES cells cultured on fixed NIH-3T3 cells for 4 days under serumfree conditions. Cells were untreated or BMP-4 treated for the last $16 \mathrm{~h}$. (b) Flow cytometric analysis of the effect of the BMP-4 overnight treatment on ES cells at day 3 of differentiation. ES cells were double stained with $\mathrm{DiOC}_{6}$ and PI. Analysed ES cells were gated according to their size (FSC) and granularity (SSC) (gate R1, upper panels). The percentage of cells within each quadrant is indicated (lower panels). Data shown are representative of five independent experiments. (c) Dose-dependent effect of BMP-4 on ES cell mitochondrial transmembrane potential. The percentages of DiOC 6 high cells (live cells) and DiOC 6 low cells (cells undergoing apoptosis) were compared between untreated and BMP-4 treated cells. Data are represented as mean \pm S.D. of control of one representative experiment performed in triplicate. (d) BMP-4 treatment of differentiating ES cells induces the cleavage of caspase-3. ES cells were treated at day 3 of differentiation with BMP-4 for 12,1416 or $18 \mathrm{~h}$. Total cell lysates were immunoblotted using anti-procaspase-3, anticleaved caspase-3 and anti- $\beta$-tubulin antibodies. Bars indicate the positions of the relative molecular weights (in $\mathrm{kDa}$ )

caspase activation occurs downstream of mitochondrial injury.

Caspase- 3 is an effector caspase that is thought to be a key executioner protease of apoptosis. During ES cell differentiation, a proportion of cells spontaneously died by apoptosis as illustrated by significant caspase-3 activation in untreated cells (Figure 2d). However, the amount of cleaved caspase-3 increased significantly after $12 \mathrm{~h}$ of BMP-4 treatment, with a peak of cleavage at $14 \mathrm{~h}$ (Figure 2d). The amount of procaspase-3 slightly decreased over time, with a minimum amount remaining at $18 \mathrm{~h}$, suggesting that the pool had not been renewed or the levels were not sufficient to cover the activation from the procaspase form to the cleaved caspase-3. 
Table 3 The activation of caspases is required for the full apoptotic process induced by BMP-4

\begin{tabular}{lcc}
\hline & & Effect of BMP-4 treatment $^{\mathbf{a}}$ \\
\cline { 2 - 3 } & Loss of DiOC $^{\text {high }}$ cells $^{\mathbf{b}}$ & Increase in DiOC $^{\text {low }}$ cells $^{\mathbf{b}}$ \\
\hline No pre-treatment & $31.3 \pm 0.9$ & $12.9 \pm 4.6$ \\
z-VAD-fmk pre-treatment & & $32.8 \pm 3.8$ \\
Student $t$-test $(P$-value) & $28.0 \pm 1.5$ & $<0.05$
\end{tabular}

${ }^{\mathrm{a}}$ Overnight BMP-4 treatment (between day 4 and day 5 of ES cell differentiation). ${ }^{\mathrm{b}} \%$ relative to cells not treated with BMP-4 (mean \pm S.D., $n=3$ ). ${ }^{\mathrm{c}}$ Pre-treatment for $4 \mathrm{~h}$ of ES cells in differentiation $(50 \mu \mathrm{M})$.
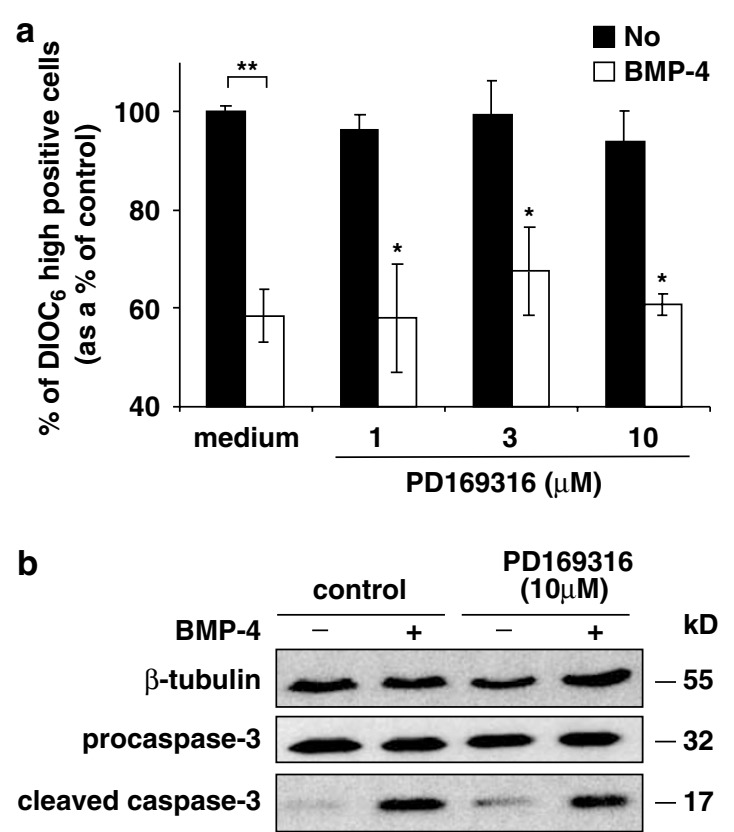

Figure 3 The p38 MAPK inhibitor PD169316 does not block apoptosis induced by BMP-4. (a) ES cells, at day 3 of differentiation, were incubated with increasing concentrations of the p38 specific inhibitor PD169316 1, 3 and $10 \mu \mathrm{M}$ for $1 \mathrm{~h}$ followed by overnight BMP-4 treatment $(0.5 \mathrm{nM})$. ES cells were then stained with $\mathrm{DiOC}_{6} / \mathrm{PI}$ and the loss of $\Delta \Psi \mathrm{m}$ was measured by flow cytometry. Data represent the mean values $( \pm S . D$.) of three experiments performed in triplicate expressed as a $\%$ of control. Statistical analyses were performed (Student $t$-test): **indicates a $P$-value $<1.5 \times 10^{-5}$ (high statistical representative difference) between untreated and BMP-4 treated cells in medium condition; * indicates a $P$-value $>0.1$ (no statistical representative difference) between untreated and PD169316 treated cells, in BMP-4 stimulated conditions. (b) ES cells at day 3 of differentiation were untreated or incubated with $10 \mu \mathrm{M}$ PD169316 for $1 \mathrm{~h}$ followed by overnight BMP-4 treatment. Total cell lysates were immunoblotted using antiprocaspase-3, anti-cleaved caspase- 3 and anti- $\beta$-tubulin antibodies. Bars indicate the positions of the relative molecular weights (in $\mathrm{kDa}$ )

Finally, we also observed externalization of phosphatidylserine, as well as sub-G1 fragmentation of DNA (not shown) confirming the induction of apoptosis after BMP-4 treatment.

\section{The p38 signaling pathway is not involved in the apoptotic process induced by BMP-4}

Several lines of evidence link the TGF- $\beta$ superfamily and the p38 MAP kinase signaling pathways, through the TAK1 MAPKKKinase ${ }^{20}$ and its activator TAB1. ${ }^{21}$ Some of the apoptotic effects of BMPs have been shown to involve the activation of $338 .^{18,22,23}$ In our cell system, we were unable to detect the activation of the p38 pathway after BMP-4 treatment. No phosphorylation of p38 nor its substrates could be detected (not shown). Furthermore, pretreatment of the differentiated ES cells with the p38 MAP kinase pathway specific inhibitor PD169316, at increasing concentrations, could not block the BMP-4-induced loss of living (DiO$\mathrm{C}_{6}(3)^{\text {high }}$ ) cells (Figure $3 a$ ). As shown in Figure $3 b$, PD169316 pretreated cells still displayed a cleaved caspase-3 when treated with BMP-4. These data clearly rule out the involvement of the p38 MAP kinase pathway in the apoptotic stimulus induced by BMP-4 on preneural differentiating ES cells.

\section{The Smad signaling pathway is required for both the inhibition of neural commitment and the apoptosis of neural precursor cells induced by BMP-4}

The intracellular Smad proteins are signaling molecules that act in the transduction of signaling pathways triggered by members of the TGF- $\beta$ family. Oligomerization of the BMP-4 receptors leads to the phosphorylation of Smad-1, which, in turn, associates with Smad-4. This multimeric complex translocates to the nucleus where it can specifically activate the transcription of numerous genes. One endogenous inhibitor of this pathway is the Smad-6 protein, which on the one hand can prevent the phosphorylation of Smad-1 by the BMP receptors, ${ }^{24}$ and on the other can associate with Smad-4 preventing its association with Smad-1. ${ }^{25}$

We used an adenoviral infection system to exogenously express Smad-6 during ES cell differentiation. ES cells were infected at day 2 of differentiation with adenoviruses (AdVs) expressing either Smad-6-flag or $\beta$-galactosidase, at similar multiplicity of infections (MOls). The Western blot analysis in Figure 4A shows that the BMP-4 treatment of ES-derived cells induced a strong and sustained phosphorylation of the Smad$1,-5$ and/or -8 molecules that was not affected by the infection with the $\beta$-galactosidase control AdV. As expected on the contrary, cells infected with the Smad-6 expressing AdV did not respond efficiently to BMP-4 treatment in terms of Smad$1,-5,-8$ induced phosphorylation.

A slight toxicity of $\mathrm{AdV}$ infection led to a reduced number of cells engaged in the differentiation process since the percentage of differentiated neurofilament-positive ES cells at day 7 was slightly reduced compared to noninfected cells (Figure 4B). Nevertheless, infected cells were still able to differentiate into neurofilament-positive neuronal cells with kinetics similar to the uninfected cells (Figure 4B and C). 
A BMP-4 for (min.) : 0 15 60

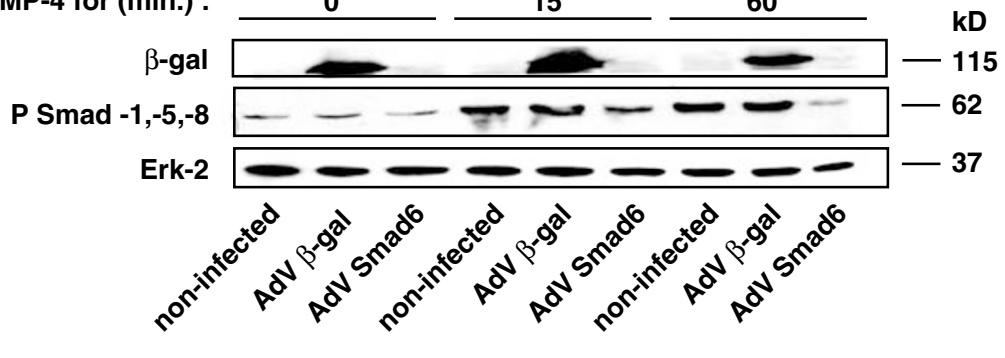

B

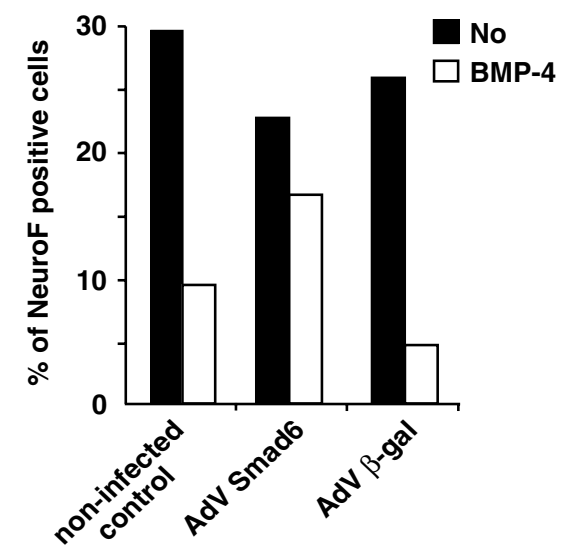

C

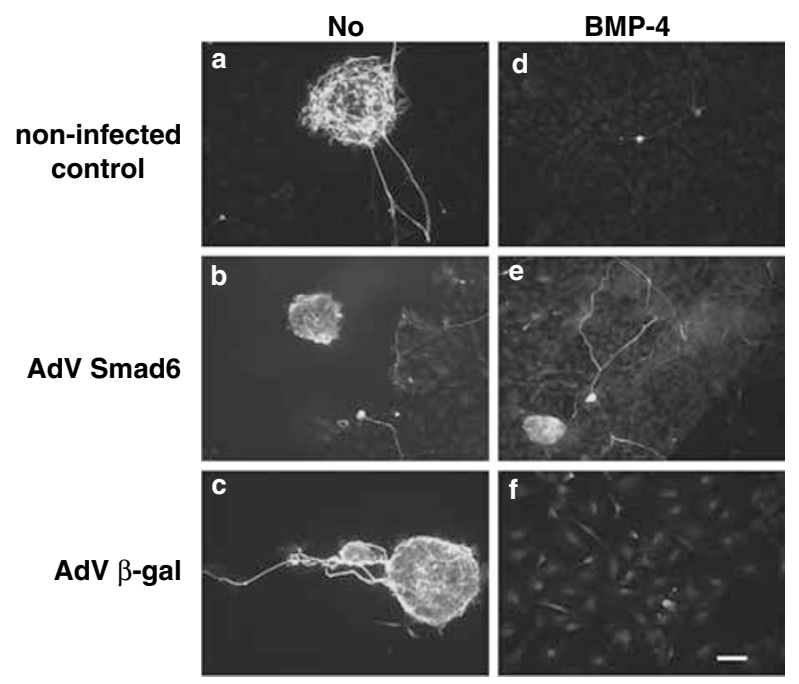

Figure 4 Smad 6 efficiently abolishes the neural inhibition induced by BMP-4 on differentiating ES cells. ES cells cultured on NIH-3T3 fixed cells were infected at day 2 of differentiation with a Smad-6-Flag adenovirus or a $\beta$-galactosidase control adenovirus. (A) At $24 \mathrm{~h}$ post-infection, cells were untreated or stimulated with BMP-4 for 15 or $60 \mathrm{~min}$. Total cell lysates were immunoblotted using anti-phopho-smad-1,-5,-8, anti- $\beta$ galactosidase and anti-Erk-2 antibodies. Bars indicate the positions of the relative molecular weights (in $\mathrm{kD}$ ). (B) At $24 \mathrm{~h}$ postinfection, cells were untreated or stimulated with BMP-4 from day 3 to day 6 . Neurofilament positive cells were quantified by flow cytometry at day 7 of differentiation. Data represent mean values of one representative experiment out of three. (C) An immunofluorescent staining was performed at day 7 on uninfected $(\mathrm{a}, \mathrm{d})$, Smad-6-flag $(\mathrm{b}, \mathrm{e})$ or $\beta$-galactosidase $(\mathrm{c}, \mathrm{f})$ infected cells untreated $(\mathrm{a}-\mathrm{c})$ or stimulated with BMP-4 (d-f) from day 3 to day 6 to visualize Neurofilament positive cells (in green). Scale bar represents $50 \mu \mathrm{m}$

Figure 5 Smad-6 prevents apoptosis of differentiated ES cells induced by BMP-4. ES cells cultured on NIH-3T3 fixed cells were infected at day 2 of differentiation with a Smad-6-Flag adenovirus or a $\beta$-galactosidase control adenovirus. At $24 \mathrm{~h}$ postinfection, cells were untreated or stimulated with BMP-4 for the next $14 \mathrm{~h}$. (a) At day $4 \mathrm{ES}$ cells were stained with $\mathrm{DiOC}_{6} / \mathrm{PI}$ and the $\Delta \Psi \mathrm{m}$ was measured by flow cytometry. The percentage of live $\left(\mathrm{DIOC}_{6}\right.$ high) cells was compared with the mean value of uninfected cells and is expressed as a percentage of control. The graph reports the mean values of two independent experiments performed in triplicate. (b) An immunofluorescent staining was performed at day 4 of differentiation to visualize cleaved caspase-3 (FITC), the exogenous Smad-6 expression (anti-Flag TxRed), and nuclei (DAPI). Scale bar represents $50 \mu \mathrm{m}$. (c) Western blots were performed with anti- $\beta$-tubulin, anti- $\beta$-galactosidase, anti-aminoterminal flag epitope of exogenous Smad-6 protein, anti-procaspase-3, and anticleaved caspase-3. Bars indicate the position of the relative molecular weights (in $\mathrm{kDa}$ ) 
a

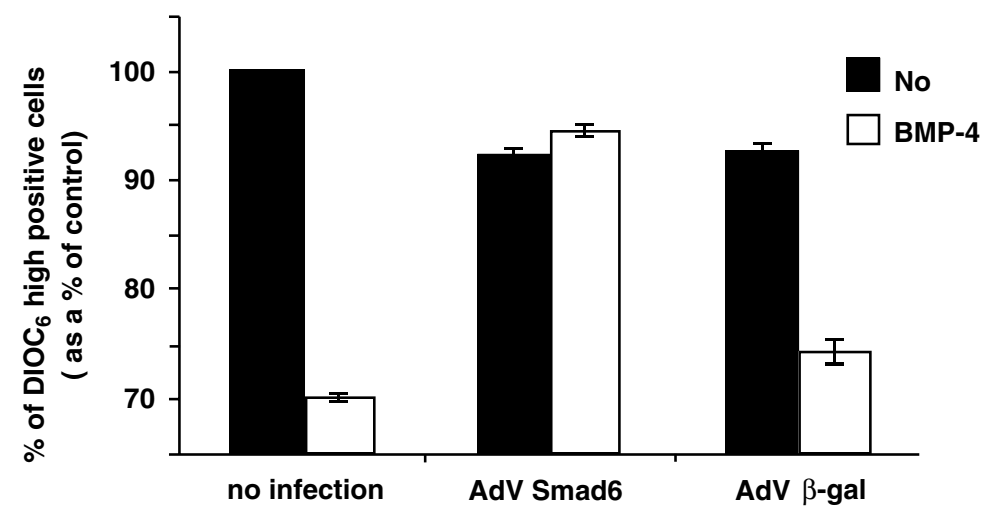

b

No

BMP-4
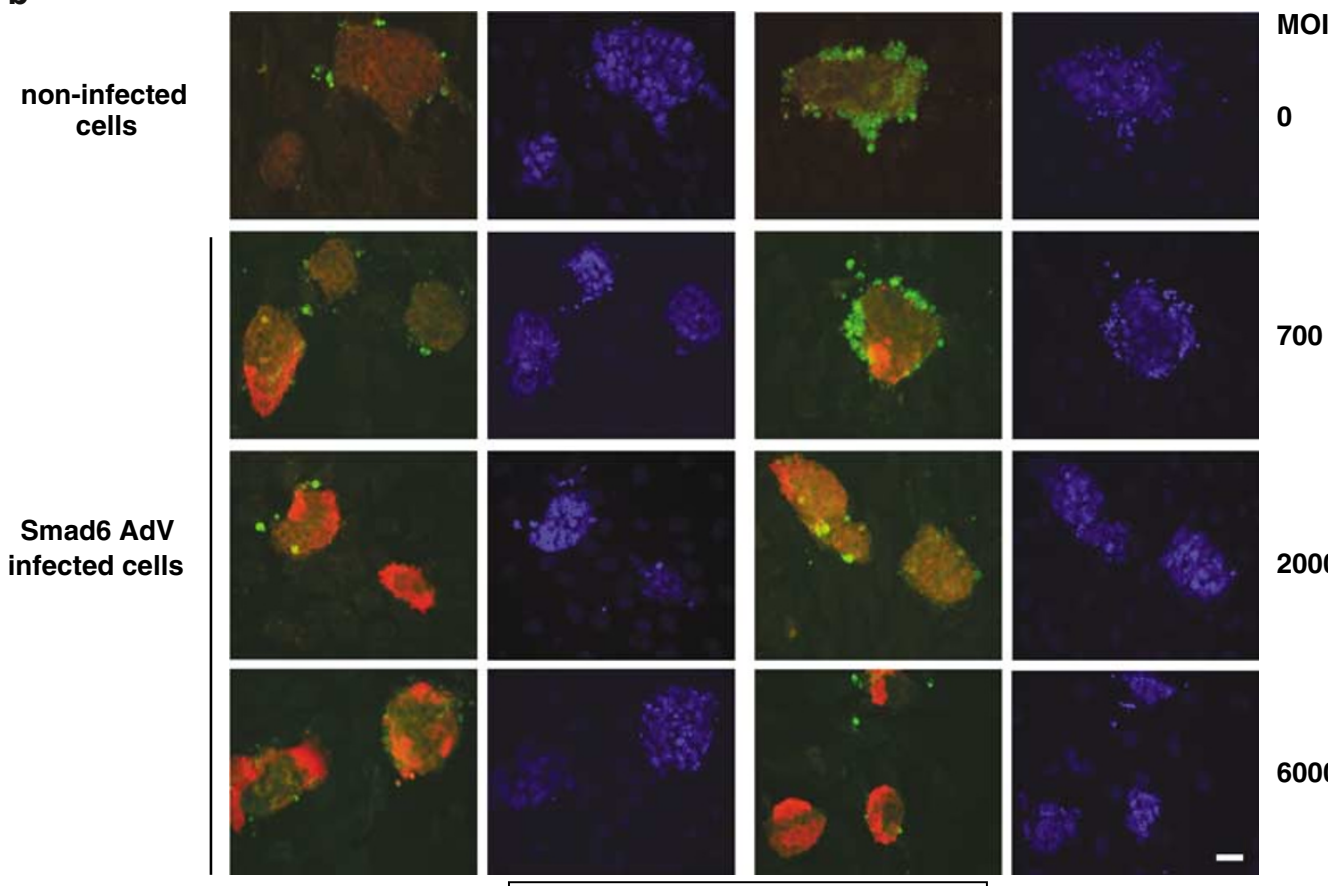

700
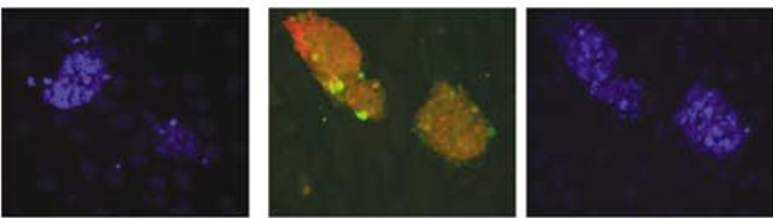

MOI
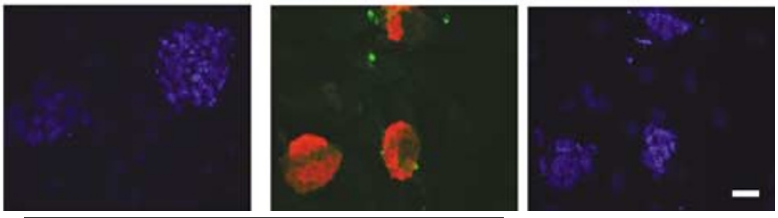

2000

Flag cleaved caspase-3 dapi

C

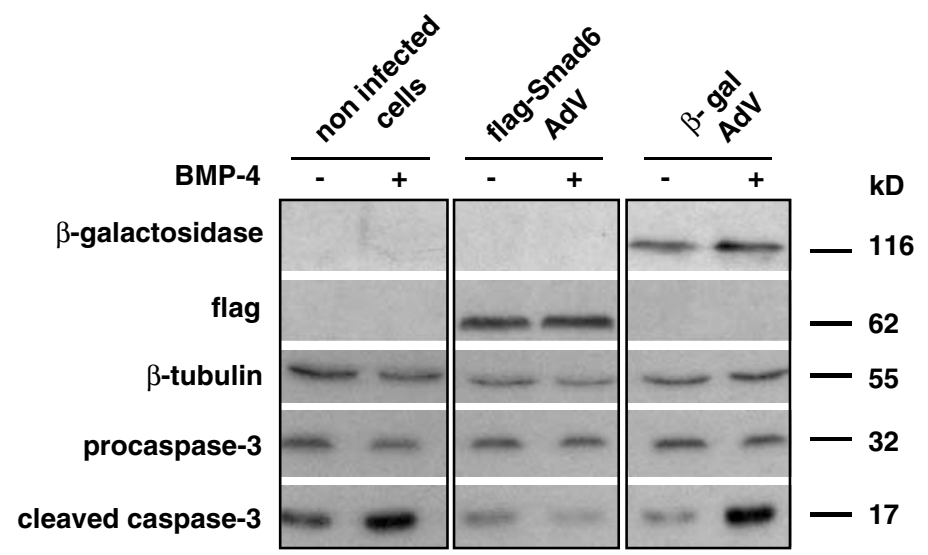


Remarkably, the AdV expression of Smad-6 efficiently blocked the inhibition of neural cell differentiation by BMP-4 (Figure 4B and C). Infection of ES cells with a $\beta$-galactosidase control AdV did not affect the neural differentiation process of the ES cells, nor its inhibition by BMP-4. We can therefore conclude that Smad-6 effectively abolishes the effect of BMP4 on neural commitment.

Accordingly, Smad-6-flag-infected ES cells were resistant to the induction of mitochondrial damage by BMP-4 treatment, as visualized by $\mathrm{DiOC}_{6}(3) / \mathrm{PI}$ staining (Figure $5 \mathrm{a}$ ). In total, $95 \%$ of BMP-4-treated, infected cells maintained their $\Delta \Psi \mathrm{m}$ compared to the percentage in uninfected cells. As a control, we show that infection with the corresponding $\beta$-galactosidase $\mathrm{AdV}$, at a similar MOI, only slightly prevented the apoptotic effect of BMP-4 (Figure 5a). Furthermore, the percentage of BMP-4-treated cells stained for activated caspase-3 dramatically decreased after Smad-6-flag AdV infection in a dosedependent manner (Figure $5 b$ ) strongly arguing that cells overexpressing Smad-6 were protected from BMP-4-induced apoptosis. This effect was not observed in cells infected with the $\beta$-galactosidase control AdV (not shown). These results were confirmed by Western blot analysis, as shown in Figure 5c. Cleavage of caspase-3 was observed in uninfected as well as $\beta$-galactosidase adenoviral-infected cells treated with BMP-4. However, it was no longer detected in Smad-6flag adenoviral infected cells treated with BMP-4 (Figure $5 \mathrm{c}$ ). Altogether, these results demonstrate that the BMP-4 induced apoptotic process requires a functional Smad pathway.

\section{BMP-4 induces apoptosis of neural precursor cells}

To determine if the ES-derived neural precursor cells are the main target of BMP-4 induced apoptosis, coimmunofluorescence staining was performed with specific antibodies against cleaved caspase-3 along with the neural markers (nestin, NeuN). Because these neural markers appeared only at day 5-6 of differentiation, BMP-4 treatment had to be performed at day 4 instead of day 3 . As stated above, detectable spontaneously apoptotic cells were present in cultures even in the absence of BMP-4 (Figure S3a,b). However, their proportions dramatically increased in the presence of BMP-4, where all the colonies bearing the neural markers displayed a much higher proportion of cells positive for activated caspase3 (Figure S3c,d). These results suggest that the cell population engaged within the neural pathway is the target of the apoptotic signal induced by BMP-4. However, the neural cells immunostained by the late markers do not colocalized by confocal analysis with the cells stained by the cleaved caspase-3 antibody (not shown). To explain this apparent discrepancy, we hypothesized that only a fraction of cells that are committed to neural fate are the target of BMP-4induced apoptosis. The Sox-1 molecule is considered as one of the earlier markers for neural precursors. Belonging to the family of the high-mobility group of transcription factors, it is first expressed in the neural plate and subsequently maintained in neuroepithelial cells throughout the entire neuraxis, but is downregulated during neuronal and glial differentiation. ${ }^{26}$ Using Sox-1-gfp ES cells, ${ }^{8}$ we quantify by flow cytometry the \% of Sox-1-positive cells during the differentiation process. As illustrated in Figure $6 \mathrm{~A}$, more than $50 \%$ of the differentiated ES cells are Sox $-1^{+}$cells at day 4, with a percentage increasing up to $70 \%$ by day 6 (not shown). The proportion of Sox-1 positive population decreases severely from 54 to $21 \%$ after BMP-4 treatment (Figure $6 \mathrm{~A}$ ), representing a loss of $60 \%$ of the Sox-1-positive population. When the absolute number of gfp-positive and gfp-negative cells remaining in the cultures before and after BMP-4 treatment was calculated, we observed that the Sox-gfp-positive cells were the main target of the BMP-4 induced apoptosis (Figure 6B).

Apoptosis of the Sox-gfp cells was quantified and the results in Figure $6 \mathrm{C}$ clearly showed that the percentage of apoptotic Sox-1 positive cells increased upon BMP-4 treatment (from 26 to 57\%) while remained similar for the Sox-1 negative cells (from 22.7 to $29 \%$ ). To further demonstrate that BMP-4 induced apoptotic cell death of neural precursor cells, confocal analysis on ES-derived colonies was performed with Sox-1 and cleaved-caspase-3 antibodies. As expected, a clear colocalization between the two markers was observed as illustrated in Figure 6D.

Finally, as expected, the inhibition of the Smad signalling pathway, through infection of Sox-1-gfp-ES-derived cells with Smad-6 overexpressing AdV, prevented the BMP-4 induced cell death of Sox-1-positive cells. The proportion of Sox1-positive cells remained stable after BMP-4 treatment of Smad-6-infected cells (Figure 6E), while it decreased equally in both noninfected and control LacZ-infected cultures.

Altogether, these results demonstrate that the BMP-4derived apoptotic signal targets the Sox-1 neural precursor cells developing in this ES-cell differentiation model.

\section{Discussion}

In lower vertebrates, BMP-4 is responsible for the inhibition of early neural cell fate determination. ${ }^{2}$ Previous studies with ES cells already strengthened the function of BMP-4, in mammals, as a key regulator of the neuroectodermal commitment. Disruption of SMAD-4-mediated BMP/TGF- $\beta$ signal transduction enhances the ability of ES cells to adopt a neural fate, which is consistent with the suppression of neural differentiation by BMP signaling. ${ }^{7}$ Exposure of ES cells to BMP-4 antagonists (recombinant noggin or transfection with a noggin-encoding plasmid) promotes the differentiation of neuro-ectodermal cells. ${ }^{27}$ The group of $\mathrm{H}$ Kawasaki has demonstrated that BMP-4 is able to redirect neuroectodermal precursors towards epidermal commitment. ${ }^{6}$ However, the mechanism of BMP-4 neural inhibition remained unexplored so far. Here, we demonstrate that BMP-4, through the Smad signaling pathway, induces the apoptotic cell death of neuroectodermal precursor cells already engaged in the neural cell fate. And similar to its in vivo effects, BMP-4 activates Msx gene expression and further commits differentiating ES cells toward surface ectodermal lineages.

Interestingly, in our differentiation process, the target cells of BMP-4 were not differentiated neurons but early precursors of neural cells. BMPs have been suggested as general inhibitors of neurogenesis through induction of apoptosis in both the central and peripheral nervous systems. They effectively inhibit proliferation and survival of neocortical 
A

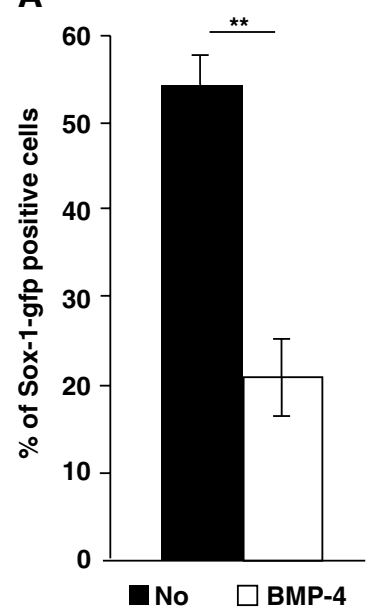

B

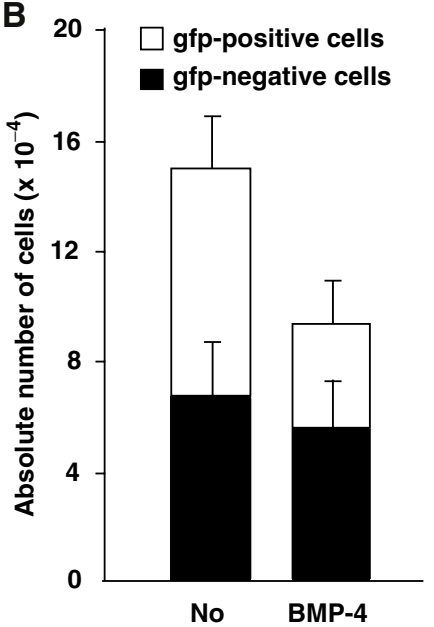

C

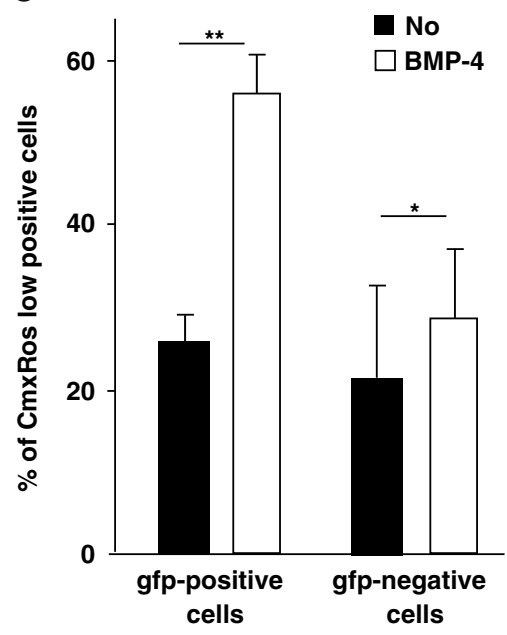

D
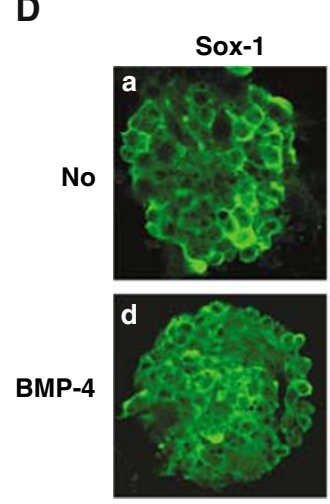

Cleaved
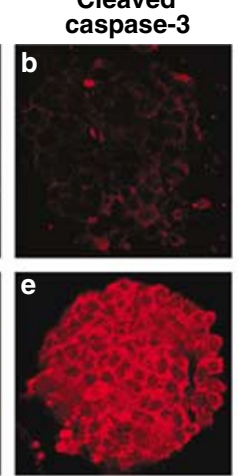

Merge
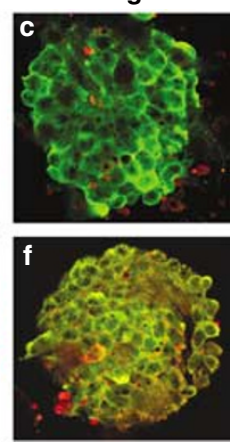

E

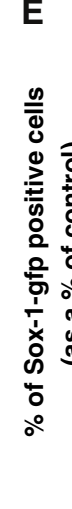

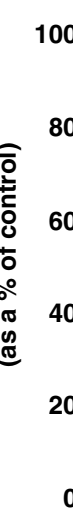

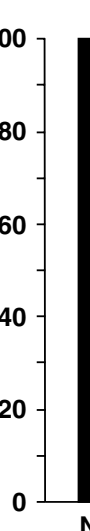

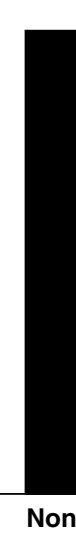

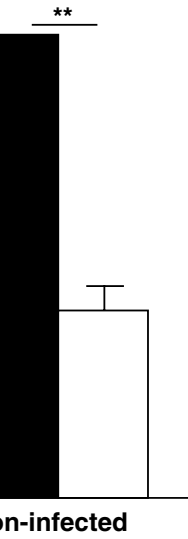

control

Figure 6 BMP-4 treatment induces the apoptotic cell death of Sox-1-positive neural precursor cells. ES cells (D) or Sox-1-gfp ES cells (A-C and E) were cultured on fixed NIH-3T3 under serum-free condition and were either untreated or stimulated overnight with BMP-4 at day 3 of differentiation. (A) Sox-1-gfp positive cells were quantified by flow cytometry at day 4 of differentiation. The percentage of sox-1-gfp positive cells decrease after the BMP-4 treatment. Data represent the mean values ( \pm S.D.) of three experiments performed in triplicate expressed as a \% of control. Statistical analysis was performed (Student's $t$-test): ** indicates a $P$-value $<1 \times 10^{-4}$ (high statistical representative difference) between untreated and BMP-4 treated cells. (B) The absolute numbers of sox-1-gfp positive and negative cells, before and after the BMP-4 treatment, show that only the sox-1-gfp positive cells were sensitive to the BMP-4 treatment. Data represent mean values of three independent experiments. (C) Apoptosis was evaluated with the fluorescent CMXRos dye at day 4 of differentiation. Percentages of apoptotic $\left(\Delta \Psi \mathrm{m}^{\text {low }}\right)$ red cells among gfp-positive and gfp-negative cells were evaluated. Data represent the mean values ( \pm S.D.) of three experiments. Statistical analysis was performed (Student's $t$-test): ${ }^{* \star}$ indicates a $P$-value $<1 \times 10^{-3}$ (high statistical representative difference) between untreated and BMP-4 treated cells. * indicates a $P$-value $>0.4$ (no statistical representative difference) between untreated and BMP-4 treated cells. (D) Cells were stained with anti Sox-1 (a and d) and with anti cleaved caspase-3 (b and e) antibodies. Confocal microscopy demonstrated that sox-1 and cleaved caspase-3 colocalize in treated conditions (e and f) compared to the untreated conditions (b and c). (E) Sox-1-gfp ES cells at day 2 of differentiation were infected with a Smad-6-Flag or a $\beta$-galactosidase control adenovirus. At $24 \mathrm{~h}$ postinfection, cells were untreated or stimulated with BMP-4. Sox-1-gfp positive cells were quantified by flow cytometry at day 4 of differentiation. Data represent the mean values $( \pm$ S.D.) of three experiments performed in triplicate expressed as a \% of control. Statistical analyses were performed (Student's $t$-test): ${ }^{* *}$ indicates a $P$-value $<6 \times 10^{-4}$ (high statistical representative difference) between untreated and BMP-4 treated cells; * indicates a $P$-value $>0.7$ (no statistical representative difference) between untreated and BMP-4 treated cells

ventricular zone ${ }^{11,16}$ and of cultured sympathetic neuroblasts. ${ }^{28,29}$ This cellular model has been previously used to differentiate rostral CNS tissues containing both ventral and dorsal cells, depending on signals delivered after the initial steps of differentiation. Dopaminergic neurons have been detected between days 6 and 8 of the induction period, following the appearance of Nestin and tubulin markers. ${ }^{6}$ Late BMP-4 exposure causes differentiation of neural crest cells and dorsalmost CNS cells, while Sonic hedgehog suppresses differentiation of neural crest lineages and promotes that of ventral CNS tissues such as motor neurons. ${ }^{30}$ In these studies $^{6}$ and in our hands, only the early exposure to BMP-4 (between day 3 and day 5) led to the inhibition of neural cell differentiation. Here we demonstrate that, even though cells expressing markers of differentiated neural cells (tubulin or NeuN), or even the undifferentiated neural progenitors Nestinpositive cells, were not the target of BMP-4 induced apoptosis, we systematically observed apoptosis in clusters where these markers were expressed. However, by detecting Sox-1, the earliest known specific marker of neuroectoderm in the mouse embryo, ${ }^{26,31}$ we were able to clearly point neural precursors cells as the targets of BMP-4 apoptosis. These results may clarify, at least in part, the molecular basis for BMP-4 inhibition of the neural fate. The question remains on the exact nature of 
the surviving precursors that still differentiate into ectodermal/ epidermal cells after BMP-4 treatment. Such committed preneural cells, emerging from a neuroectodermal precursor, have been described in other ES-derived neural differentiation studies. ${ }^{7,32}$ Molecular characterization of these cells would be of interest to study the function of BMP-4 on neuro-ectodermal commitment.

Tested in the presence of Smad-6, BMP-4 no longer prevented neural differentiation of ES cells, demonstrating that in mouse ES cells, inhibition of neural differentiation induced by BMP-4 required the Smad pathway. Furthermore, the BMP-4-dependent apoptotic process was inhibited in Smad-6-infected cells, both at the level of mitochondrial perturbation and the caspase-3 activation. These results demonstrate that BMP-4 requires a functional Smad signaling pathway to induce both apoptosis and neural cell differentiation inhibition.

The apoptotic cell death reported here is characterized by the typical apoptotic mitochondrial damage and the activation of caspase-3. Fujita et al. ${ }^{33}$ reported that BMP-4 induces apoptosis of RA-dependent neural differentiating P19 carcinoma cells ${ }^{34}$ through the direct activation of caspase-9, upstream of caspase-3 and with no involvement of the classical mitochondrial pathway involving the Apaf-1/cytochrome c complex. In the present model, the broad caspase inhibitor z-VAD-fmk efficiently prevented cell death but was unable to block mitochondrial damage, ruling out a direct activation of the caspase- 9 as the mechanism of apoptotic induction by BMP-4. This suggests that activation of caspases occurred downstream of the mitochondrial damage and that apoptosis was not induced through the activation of apical activator caspases (such as caspase- 8 activated by Death Effector Domain proteins - FAS, TRAIL or TNF-R family members).

Protein synthesis is required for mitochondrial injury to proceed in our model, indicating that the BMP-4-dependent signaling pathway regulates the transcription of specific genes. Indeed, known genes activated in response to BMP4 signaling were largely transcribed. Among them, the transcriptional regulator Msx-2 has been reported as a BMP target gene in apoptosis of rhombencephalic neural crest cells, ${ }^{12}$ chick limb, ${ }^{14,35}$ calvarial bone ${ }^{36}$ and other tissues. ${ }^{37}$ The nature of the genes activated by Msx-2 expression and leading to apoptosis are not yet defined. A fine balance between pro- and antiapoptotic molecules, such as Bcl-2 family members, is required to control the integrity of the mitochondrial transmembrane potential. Whether this balance is subjected to regulation by Msx-2 expression can be questionned. For instance, the apoptosis of ventricular zone progenitor cells induced by BMP-4/Msx-2 was suggested to involve bax-independent, as well as bax-dependent cell death pathways, ${ }^{38}$ but with no evidence of the relationship between Msx-2 transcription and Bax level modulation. The expression level of such molecules, or their relocalization from or to the mitonchondial membrane, in preliminary tests, do not change during the early steps of the apoptotic mechanism in our conditions (not shown), but further investigation has to be undertaken.

We demonstrate here for the first time the involvement of early neural progenitor apoptotic cell death in the inhibition of neuralization triggered by BMP-4. In vitro ES cell differentiation is a powerful model to study early mammalian development. Based on this model, we propose, here, that, in mammals, BMP-4 controls the fate of ectodermal progenitors - progenitors of both neuroectoderm and surface ectoderm toward the formation of epidermis while inhibiting neural differentiation through an apoptotic mechanism. Such a model will be an invaluable tool to decrypt the full range of molecular events involved.

\section{Materials and Methods}

\section{ES cell culture and in vitro differentiation}

The undifferentiated mouse ES cell lines CGR8 and CGR8 Sox 1 GFP (ES cell line from transgenic mouse in which the enhanced GFP reporter is inserted into the sox 1 gene via gene targeting ${ }^{8}$ ) were routinely cultured in flasks coated with $0.1 \%$ gelatin (GIBCO-BRL, Invitrogen, France) diluted in PBS pH 7.2 (GIBCO-BRL). The culture medium was composed of BHK-21 (GIBCO-BRL) supplemented with 10\% fetal bovine serum (Hyclone, Perbio Science, France), 1\% nonessential amino acids (GIBCO-BRL), $1 \mathrm{mM}$ sodium pyruvate (GIBCO-BRL), $0.1 \mathrm{mM} \beta$-mercaptoethanol (GIBCO-BRL) and $10^{3} \mathrm{U} / \mathrm{ml}$ LIF (Leukemia Inhibitory Factor, our own production).

For neural differentiation, ES cells were cultured in BHK-21 supplemented with $10 \% \mathrm{KSR}$ (GIBCO-BRL), 1\% nonessential amino acids, $1 \mathrm{mM}$ sodium pyruvate and $0.1 \mathrm{mM} \beta$-mercaptoethanol (differentiation medium) on fixed $\mathrm{NIH}-3 \mathrm{~T} 3$ cells. It was essential to remove serum from the medium since the addition of fetal bovine serum strongly inhibited neural differentiation.

\section{Formaldehyde treatment of NIH-3T3 cells}

$\mathrm{NIH}-3 \mathrm{~T} 3$ cells grown to confluency were fixed with $3 \%$ formaldehyde in PBS (Sigma-Aldrich, France) for 15 min at room temperature, washed with PBS and incubated with glycine (1 mM) (ICN Pharmaceuticals, France) at room temperature for 15 min to saturate free formaldehyde sites. Dishes or coverslips were stored in PBS at $4^{\circ} \mathrm{C}$ until use for ES cells differentiation.

\section{Treatment with BMP-4 and biochemical inhibitors}

ES cells were cultured on fixed NIH-3T3 cells in differentiation medium and $0.5 \mathrm{nM}$ human recombinant BMP-4 (R\&D Systems Europe, UK) was added to the medium at the indicated timepoints. For apoptosis assay, BMP-4 was added for $12-18 \mathrm{~h}$ on day 3 of differentiation. For epidermal differentiation assays, ES cells were cultured for 8 days and BMP-4 was added each day from day 3 to day 5 . PD169316 (1, 3 and $10 \mu \mathrm{M})$ (Calbiochem, VWR International SAS, France) and cycloheximide $(10 \mu \mathrm{M})$ (Sigma-Aldrich) were added $1 \mathrm{~h}$ prior to BMP-4 treatment. For caspase inhibition, cells were preincubated for $4 \mathrm{~h}$ with z-VAD-fmk $(50 \mu \mathrm{M})$ (Alexis Corporation, Switzerland).

\section{Antibodies and immunofluorescence}

ES cells grown on fixed NIH-3T3 cells (on coated coverslips) for 4 or 8 days in differentiation medium were fixed in PBS-formaldehyde $3 \%$ at $4{ }^{\circ} \mathrm{C}$ for $15 \mathrm{~min}$ and were then incubated with PBS containing $3 \%$ bovine serum albumin (Sigma-Aldrich) for $30 \mathrm{~min}$ at room temperature. They were then stained with primary antibodies for $60 \mathrm{~min}$ in $3 \%$ PBS-BSA, washed, and incubated with secondary antibodies for $60 \mathrm{~min}$ in $3 \%$ PBS-BSA. The cell 
nuclei were stained with Hoechst 33342 bis benzimide (Sigma-Aldrich). Mounted coverslips were analysed under an Axiophot microscope with objective lenses Neofluor (Zeiss, Oberkochen). Images were acquired with a black and white Cohn camera piloted by the Qfish acquisition softwar (Leica, Heidelberg, Germany).

The primary antibodies used for immunofluorescence were: mouse anti-human cytokeratin 14 (clone NCL-L-LL02; Novocastra Laboratories, Tebu International, France), anti-Nestin (clone RAT401, PharMingen, BD Biosciences, France), anti-NeuN (Chemicon, Euromedex, France), antitubulin beta III (Chemicon) and anti-Flag M2 (Sigma-Aldrich); rabbit polyclonal antibodies anti-cleaved caspase-3 (Cell Signaling Technologies, Ozyme, France), and anti-neurofilaments (Affinity Research Products, Tebu International, France). Secondary goat anti-mousecoupled Texas Red antibody was purchased from Molecular Probes (Invitrogen, France), FITC rabbit anti-mouse and swine anti-rabbit antibodies were purchased from Dako (Dako A/S, Denmark). For all studies, negative controls were performed by omitting the primary antibodies.

\section{Confocal microscopy}

ES cells cultured on fixed NIH-3T3 cells for 4 days under serum-free conditions were untreated or BMP-4 treated for the last $14 \mathrm{~h}$. Cells were fixed in $3 \%$ formaldehyde for $20 \mathrm{~min}$ at room temperature, satured and permeabilized with PBS-2.5\% donkey serum (Jackson Immuno Research, Interchim, France), 2.5\% rabbit serum (Dakko A/S), 0.2\% Triton X-100 for $30 \mathrm{~min}$. Permeabilized cells were incubated with rabbit polyclonal anticleaved caspase-3 (Cell Signaling Technologies) and with chicken polyclonal anti-Sox-1 (Chemicon) antibodies in 3\% PBS-BSA for $1 \mathrm{~h}$ at room temperature. After three washes with PBS $0.2 \%$ Triton X-100, cells were incubated with the appropriate fluorescent-conjugated secondary antibodies for $1 \mathrm{~h}$ at room temperature. Cells were then washed three times with PBS $0.2 \%$ Triton and mounted on glass slides in Mowiol 4-88 (Calbiochem). Slides were finally examined and photographed with a TCS-SP confocal microscope (Leica) using a $\times 63$ magnification lens.

\section{RT-PCR}

Total RNA was extracted using Trizol reagent (Invitrogen, France) and incubated with DNase I (Ambion) according to the manufacturer's instructions to minimize genomic DNA contamination. The cDNA was synthesized ( $2 \mu \mathrm{g}$ RNA per condition) using the PowerScript Reverse Transcriptase (Clontech, Ozyme, France). The cDNA was analysed by PCR amplification using individual primer pairs for specific marker genes. The following oligonocleotide primer sequences and annealing temperatures were used:

\section{GFAP (sense, $5^{\prime}$ CTGTTTGCCAGGCTCAGTTCCCAC}

$3^{\prime}$; antisense, $5^{\prime}$ GGAAACTTCCAGCTCTGGAACGG; $67^{\circ} \mathrm{C}$ ). Brachyury (sense, $5^{\prime}$ GCTCATCGGAACAGCTCTCCAACC $3^{\prime}$; antisense, $5^{\prime}$ GGAGAACCAGAAGACGAGGACGTG $3^{\prime} ; 67^{\circ} \mathrm{C}$ ). AFP (sense, $5^{\prime}$ CCTTGGCTGCTCAGTACGACAAGG $3^{\prime}$; antisense, $5^{\prime}$ CCTGCAGACACTCCAGCGAGTTTC $3^{\prime} ; 67^{\circ} \mathrm{C}$ ). MAP2 (sense, $5^{\prime}$ AGCCGCAACGCCAATGGATT $3^{\prime}$; antisense, $5^{\prime}$ TTTGTTCCGAGGCTGGCGAT $3^{\prime} ; 58^{\circ} \mathrm{C}$ ). Sox-1 (sense, $5^{\prime}$ CTGCTCAAGAAGGACAAGTA $3^{\prime}$; antisense, $5^{\prime}$ CTCATGTAGCCCTGAGAGT $3^{\prime} ; 52^{\circ} \mathrm{C}$ ). Sox-10 (sense, 5' CGGTGAACTGGGCAAGGTCA $3^{\prime}$; antisense, $5^{\prime}$ AGCTCTGTCTTTGGGGTGGTTGGA $3^{\prime} ; 59^{\circ} \mathrm{C}$ ).
Actin (sense, $5^{\prime}$ GTTTGAGACCTTCAACACCCC $3^{\prime}$; antisense, $5^{\prime}$ GTGGCCATCTCCTGCTCGAAGTC $3^{\prime} ; 62^{\circ} \mathrm{C}$ ).

The PCR products were then separated on $1 \%$ agarose gel and visualized by ethidium bromide fluorescence.

\section{Real-time quantitative RT-PCR}

RNAs were extracted using Trizol reagent (Invitrogen) either 2 or $24 \mathrm{~h}$ after stimulation with BMP-4, to measure Msx-1, Msx-2 and Id-3 expression and incubated with DNasel (Ambion), according to the manufacturer's instructions to minimize genomic DNA contamination. The cDNA was synthesized using the PowerScript Reverse Transcriptase (Clontech, Ozyme). The relative expression level of transcripts was quantified by realtime RT-PCR using the SYBR-Green PCR Master Mix on an ABI PRISM 7700 Sequence Detection System (Applied Biosystems, France), according to the manufacturer's instructions. Each reaction mixture contained a $300 \mathrm{nM}$ concentration of each primer and $5 \mu \mathrm{l}$ of cDNA product diluted 1:25 were used. The relative amount of each gene to 36B4 internal control and the fold stimulation was calculated by using equation (2) ${ }^{-\Delta \Delta C T}$, where $\Delta \mathrm{CT}=\mathrm{CT}_{\text {gene }}-\mathrm{CT}_{36 \mathrm{~B} 4}$ and $\Delta \Delta \mathrm{CT}=$ $\Delta \mathrm{CT}_{\text {stimulated condition }}-\Delta \mathrm{CT}_{\text {unstimulated condition. Each gene was amplified }}$ using the appropriate specific primers (sequences available upon request). The results are the average of three separate experiments.

\section{FACS analysis}

Neural and epithelial determination

ES cells cultured on fixed NIH-3T3 cells were detached with PBS-0.5\% BSA-0.5 mM EDTA. They were fixed in $2 \%$ formaldehyde in PBS, permeabilized in PBS-0.5\% saponin (Sigma-Aldrich)-0.5\% BSA for $10 \mathrm{~min}$ and saturated with PBS- $0.5 \%$ saponin- $0.5 \%$ BSA- $-0.5 \%$ rabbit or swine serum following secondary antibodies for $30 \mathrm{~min}$. They were stained with rabbit antineurofilaments mAb (Affinity Research Products) or with mouse anti-Keratin 18 MAB3234 (Chemicon), mAb for $45 \mathrm{~min}$. Mouse isotype control $\mathrm{mAb}$ (PharMingen) and control rabbit serum was used to set the background level of fluorescence. Rabbit anti-mouse and swine anti-rabbit coupled FITC antibodies (Dakko A/S) were added for $45 \mathrm{~min}$. Cells were monitored by flow cytofluorometry on a FACScan system using CellQuest software (BD Biosciences).

\section{DiOC6/IP determination}

Mitochondrial injury, leading to the decrease of the mitochondrial transmembrane potential $(\Delta \Psi \mathrm{m})$ is an early and irreversible step in the process of apoptosis. Thus, apoptosis can be measured and quantified by flow cytometric analysis, with the fluorescent probe $3,3^{\prime}$ dihexyloxacarbocyanine iodide $\left(\mathrm{DiOC}_{6}(3)\right)$, which is a lipophilic cationic fluorochrome that accumulates in the matrix of mitochondria proportionally to their transmembrane potential. A double staining with PI (which labels dead cells that have lost the integrity of their cytoplasmic membrane) and $\mathrm{DiOC}_{6}(3)$ discriminates between dead cells $\left(\mathrm{DiOC}_{6}(3)^{\mathrm{low}} / \mathrm{PI}{ }^{+}\right)$, live cells $\left(\mathrm{DiOC}_{6}(3)^{\text {high }} / \mathrm{PI}^{-}\right)$and apoptotic cells $\left(\mathrm{DiOC}_{6}(3)^{\text {low }} / \mathrm{PI}^{-}\right)$. Differentiated ES cells were detached from the six-well plates and pooled with spontaneously detached cells present in cell culture supernatants. After washing, cells were resuspended in differentiation medium and incubated for $15 \mathrm{~min}$ at $37^{\circ} \mathrm{C}$ with $50 \mathrm{nM} \mathrm{DiOC}_{6}$ (Molecular Probes) and with $5 \mu \mathrm{g} / \mathrm{ml}$ $\mathrm{PI}$ (Sigma-Aldrich) at $4^{\circ} \mathrm{C}$ for $5 \mathrm{~min}$. At least 10000 cells were analysed on a FACScan. 


\section{CMXRos determination}

Changes in $\Delta \Psi \mathrm{m}$ of Sox-1-gfp ES cells were evaluated by cytofluorometry with the potential sensitive red fluorescent probe chloromethylX-rosamine (100 nM) (CMXRos, Molecular Probes).

\section{Sox-1-GFP determination}

ES Sox-1-GFP cultured on fixed NIH-3T3 cells for 4 days were detached with PBS- $0.5 \%$ BSA-0.5\% mM EDTA, resuspended in cold PBS and counted. They were then analysed by flow cytometry: viable cells were gated according to their size (FCS) and granularity (SSC) and gates were set according to the gfp fluorescence. The $\%$ and absolute numbers of Sox-1-gfp-positive cells and gfp-negative cells were determined.

\section{Transient adenoviral infection of smad 6 and $\beta$-galactosidase genes}

Adenoviral stocks (obtained from Dr. A Moustakas, Ludwig Institue for Cancer Research, Uppsala, Sweden) were maintained in 293 cells as described by Fujii; ${ }^{39}$ their titres ranged from 1 to $4 \times 10^{9}$ plaque forming units (PFU) per millilitre. Infections were performed at a maximal $\mathrm{MOI}$ of 6000 . Controls were performed using a $\beta$-galactosidase-encoding virus and the cells were stained with 5-bromo-4-chloro-3-indolyl- $\beta$-D-galactoside (X-Gal, Eurogentec, France) as described by Fujii et al. ${ }^{39}$ Relatively high $\mathrm{MOI}$ had to be used in order to overexpress the Smad- 6 as well as the control $\beta$-Gal proteins, but the use of similar MOI with similar viruses was published in mammary carcinoma cells. ${ }^{40}$ Nevertheless, transgenes were transcribed efficiently (Figures $4 \mathrm{~A}$ and $5 \mathrm{~B}$ ), and despite the slight cell toxicity of the $\mathrm{AdV}$, no perturbation in the commitment to the neural cell lineage was observed (Figure 4C). Under optimal conditions, more than $90 \%$ of the cells were infected. ES cells were cultured in six-well plates and were infected after 2 days of differentiation for $1 \mathrm{~h}$ in a low volume of culture medium. Fresh medium was then added and $48 \mathrm{~h}$ after infection, cells were washed and treated with BMP-4.

\section{Immunoblotting}

Differentiated ES cells were cultured in $60 \mathrm{~mm}^{2}$ dishes, treated with BMP-4 and infected as described in the figure legends. Then, the cells were lysed in buffer containing $50 \mathrm{mM}$ Tris $\mathrm{pH} 7.4,150 \mathrm{mM} \mathrm{NaCl}, 1 \%$ Triton X$100,10 \mu \mathrm{M}$ leupeptin, $1 \mathrm{mM}$ AEBSF, $100 \mathrm{U} / \mathrm{ml}$ aprotinin, $10 \mathrm{mM} \mathrm{NaF}$ and $1 \mathrm{mM} \mathrm{Na}_{3} \mathrm{VO}_{4}$. Samples (50 $\mu \mathrm{g}$ of proteins) were resolved by $12 \%$ SDSPAGE, transferred onto Hybond C Extra nitrocellulose membranes (Amersham Biosciences, France), and then incubated with the appropriate antibodies: rabbit polyclonal antibodies raised against the zymogen and the cleaved form of caspase 3 (Cell Signaling Technologies), the phosphosmad-1, -5, -8 (generous gift from Dr C-H Heldin, Ludwig Institute for Cancer Research, Uppsala, Sweden), mouse monoclonal antibody raised against Flag M2 (Sigma-Aldrich), mouse ascites fluid raised against $\beta$ tubulin clone TUB2.1 (Sigma-Aldrich), rabbit IgG fraction raised against $\beta$ galactosidase (ICN Pharmaceuticals) and mouse monoclonal IgG2b antibody raised against Erk-2 (Santa Cruz Biotechnology, Tebu International). Proteins were visualized with the ECL system (Amersham) using HRP-conjugated anti-rabbit or anti-mouse secondary antibodies.

\section{Acknowledgements}

We thank Dr. A Moustakas and Dr. C-H Heldin, from the Ludwig Institute for Cancer Research (Uppsala, Sweden), for the generous gift of the adenoviruses AdV-LacZ and AdV-Smad-6, and the antiphospho smad-
1,5,8 antibody, respectively; Dr. R Lowell-Badge from the MRC (London, UK) for the generous gift of the anti-sox-1 antibody. We also thank Dr. B Koppelman and Dr. R Barthel for critical reading of the manuscript. This research was supported by a grant from INSERM, the Association Française contre la Myopathie, Vaincre la Mucoviscidose, Ministère de la Recherche (ATC 2002 - Biothérapie), the Association pour la Recherche sur le Cancer and the Société de Recherche en Dermatologie.

\section{References}

1. Hogan BL (1996) Bone morphogenetic proteins: multifunctional regulators of vertebrate development. Genes Dev. 10: 1580-1594

2. Hemmati-Brivanlou A and Melton D (1997) Vertebrate neural induction. Annu. Rev. Neurosci. 20: 43-60

3. Chang C and Hemmati-Brivanlou A (1998) Cell fate determination in embryonic ectoderm. J. Neurobiol. 36: 128-151

4. Munoz-Sanjuan I and Brivanlou AH (2002) Neural induction, the default model and embryonic stem cells. Nat. Rev. Neurosci. 3: 271-280

5. Finley MF, Devata S and Huettner JE (1999) BMP-4 inhibits neural differentiation of murine embryonic stem cells. J. Neurobiol. 40: 271-287

6. Kawasaki H, Mizuseki K, Nishikawa S, Kaneko S, Kuwana Y, Nakanishi S, Nishikawa SI and Sasai Y (2000) Induction of midbrain dopaminergic neurons from ES cells by stromal cell-derived inducing activity. Neuron 28: 31-40

7. Tropepe V, Hitoshi S, Sirard C, Mak TW, Rossant J and van der Kooy D (2001) Direct neural fate specification from embryonic stem cells: a primitive mammalian neural stem cell stage acquired through a default mechanism. Neuron 30: 65-78

8. Ying QL, Stavridis M, Griffiths D, Li M and Smith A (2003) Conversion of embryonic stem cells into neuroectodermal precursors in adherent monoculture. Nat. Biotechnol. 21: 183-186

9. Suzuki A, Ueno N and Hemmati-Brivanlou A (1997) Xenopus msx1 mediates epidermal induction and neural inhibition by BMP4. Development 124: 3037-3044

10. Coucouvanis E and Martin GR (1999) BMP signaling plays a role in visceral endoderm differentiation and cavitation in the early mouse embryo. Development 126: 535-546

11. Furuta $Y$, Piston DW and Hogan BL (1997) Bone morphogenetic proteins (BMPs) as regulators of dorsal forebrain development. Development 124: 2203-2212

12. Graham A, Francis-West $P$, Brickell $P$ and Lumsden $A$ (1994) The signalling molecule BMP4 mediates apoptosis in the rhombencephalic neural crest. Nature 372: 684-686

13. Trousse F, Esteve P and Bovolenta P (2001) Bmp4 mediates apoptotic cell death in the developing chick eve. J. Neurosci. 21: 1292-1301

14. Zou $H$ and Niswander $L$ (1996) Requirement for BMP signaling in interdigital apoptosis and scale formation. Science 272: 738-741

15. Gross RE, Mehler MF, Mabie PC, Zang Z, Santschi L and Kessler JA (1996) Bone morphogenetic proteins promote astroglial lineage commitment by mammalian subventricular zone progenitor cells. Neuron. 17: 595-606

16. Mabie PC, Mehler MF and Kessler JA (1999) Multiple roles of bone morphogenetic protein signaling in the regulation of cortical cell number and phenotype. J. Neurosci. 19: 7077-7088

17. Coraux C, Hilmi C, Rouleau M, Spadafora A, Hinnrasky J, Ortonne JP, Dani C and Aberdam D (2003) Reconstituted skin from murine embryonic stem cells. Curr. Biol. 13: 849-853

18. Kimura N, Matsuo R, Shibuya H, Nakashima K and Taga T (2000) BMP2induced apoptosis is mediated by activation of the TAK1-p38 kinase pathway that is negatively regulated by Smad6. J. Biol. Chem. 275: 17647-17652

19. Barberi T, Klivenyi P, Calingasan NY, Lee H, Kawamata H, Loonam K, Perrier AL, Bruses J, Rubio ME, Topf N, Tabar V, Harrison NL, Beal MF, Moore MA and Studer $L$ (2003) Neural subtype specification of fertilization and nuclear transfer embryonic stem cells and application in parkinsonian mice. Nat. Biotechnol. 21: 1200-1207

20. Yamaguchi K, Shirakabe K, Shibuya H, Irie K, Oishi I, Ueno N, Taniguchi T, Nishida E and Matsumoto K (1995) Identification of a member of the MAPKKK 
family as a potential mediator of TGF-beta signal transduction. Science 270 : 2008-2011

21. Shibuya H, Yamaguchi K, Shirakabe K, Tonegawa A, Gotoh Y, Ueno N, Irie K, Nishida E and Matsumoto K (1996) TAB1: an activator of the TAK1 MAPKKK in TGF-beta signal transduction. Science 272: 1179-1182

22. Hallahan AR, Pritchard JI, Chandraratna RA, Ellenbogen RG, Geyer JR, Overland RP, Strand AD, Tapscott SJ and Olson JM (2003) BMP-2 mediates retinoid-induced apoptosis in medulloblastoma cells through a paracrine effect. Nat. Med. 9: 1033-1038

23. Kendall SE, Battelli C, Irwin S, Mitchell JG, Glackin CA and Verdi JM (2005) NRAGE mediates p38 activation and neural progenitor apoptosis via the bone morphogenetic protein signaling cascade. Mol. Cell. Biol. 25: 7711-7724

24. Imamura T, Takase M, Nishihara A, Oeda E, Hanai J, Kawabata M and Miyazono K (1997) Smad6 inhibits signalling by the TGF-beta superfamily. Nature 389: 622-626

25. Hata A, Lagna G, Massague J and Hemmati-Brivanlou A (1998) Smad6 inhibits BMP/Smad1 signaling by specifically competing with the Smad4 tumor suppressor. Genes Dev. 12: 186-197

26. Wood HB and Episkopou V (1999) Comparative expression of the mouse Sox1 Sox2 and Sox3 genes from pre-gastrulation to early somite stages. Mech. Dev. 86: 197-201

27. Gratsch TE and O'Shea KS (2002) Noggin and chordin have distinct activities in promoting lineage commitment of mouse embryonic stem (ES) cells. Dev. Biol. 245: 83-94

28. Gomes WA and Kessler JA (2001) Msx-2 and p21 mediate the pro-apoptotic but not the anti-proliferative effects of BMP4 on cultured sympathetic neuroblasts. Dev. Biol. 237: 212-221

29. Song Q, Mehler MF and Kessler JA (1998) Bone morphogenetic proteins induce apoptosis and growth factor dependence of cultured sympathoadrenal progenitor cells. Dev. Biol. 196: 119-127

30. Mizuseki K, Sakamoto T, Watanabe K, Muguruma K, Ikeya M, Nishiyama A, Arakawa A, Suemori H, Nakatsuji N, Kawasaki H, Murakami F and Sasai $Y$ (2003) Generation of neural crest-derived peripheral neurons and floor plate cells from mouse and primate embryonic stem cells. Proc. Natl. Acad. Sci. USA 100: 5828-5833

31. Pevny LH, Sockanathan S, Placzek M and Lovell-Badge R (1998) A role for SOX1 in neural determination. Development 125: 1967-1978

32. Rathjen J, Haines BP, Hudson KM, Nesci A, Dunn S and Rathjen PD (2002) Directed differentiation of pluripotent cells to neural lineages: homogeneous formation and differentiation of a neurectoderm population. Development 129: 2649-2661

33. Fujita E, Soyama A, Kawabata M and Momoi T (1999) BMP-4 and retinoic acid synergistically induce activation of caspase-9 and cause apoptosis of P19 embryonal carcinoma cells cultured as a monolayer. Cell Death Differ. 6: 1109-1116

34. Glozak MA and Rogers MB (1996) Specific induction of apoptosis in P19 embryonal carcinoma cells by retinoic acid and BMP2 or BMP4. Dev. Biol. 179: 458-470

35. Ferrari D, Lichtler AC, Pan ZZ, Dealy CN, Upholt WB and Kosher RA (1998) Ectopic expression of Msx-2 in posterior limb bud mesoderm impairs limb morphogenesis while inducing BMP-4 expression, inhibiting cell proliferation, and promoting apoptosis. Dev. Biol. 197: 12-24

36. Rice DP, Kim HJ and Thesleff I (1999) Apoptosis in murine calvarial bone and suture development. Eur. J. Oral Sci. 107: 265-275

37. Marazzi G, Wang Y and Sassoon D (1997) Msx2 is a transcriptional regulator in the BMP4-mediated programmed cell death pathway. Dev. Biol. 186: 127-138

38. Israsena N and Kessler JA (2002) Msx2 and p21(CIP1/WAF1) mediate the proapoptotic effects of bone morphogenetic protein-4 on ventricular zone progenitor cells. J. Neurosci. Res. 69: 803-809

39. Fujii M, Takeda K, Imamura T, Aoki H, Sampath TK, Enomoto S, Kawabata M, Kato M, Ichijo H and Miyazono K (1999) Roles of bone morphogenetic protein type I receptors and Smad proteins in osteoblast and chondroblast differentiation. Mol. Biol. Cell 10: 3801-3813

40. Kowanetz M, Valcourt U, Bergstrom R, Heldin CH and Moustakas A (2004) Id2 and Id 3 define the potency of cell proliferation and differentiation responses to transforming growth factor beta and bone morphogenetic protein. Mol. Cell. Biol. 24: 4241-4254

\section{Supplementary Information accompanies the paper on Cell Death and Differentiation website (http://www.nature.com/cdd)}

